\title{
Tiempo nuevo: un Beckett para cada momento ¡OTRO DÍA FELIZ!
}

๑ Por Luis Mazas

Winnie es una señora amable e insufrible; convencional y de mediana edad. Se va hundiendo paulatinamente en el suelo mientras acepta ese día a día, con gran optimismo inmediato. ¿Resignación? Y un tanto de negación acaso, entretenida en lo cotidiano, lo intrascendente. Winnie espera que todo se repita una vez más en la rutina, y nada se altere. Necesita que su marido Willie, allá cerca y en lo suyo, cada tanto le dé señales de vida, de algún interés; la confirme en su existir. En Los días felices ella parlotea y parlotea en un soliloquio casi continuo. En escena está el Tiempo, el tercer silencioso personaje que desdice lo estable de la rutina; de la felicidad posible. Lo inalterable de la existencia. La angustia que genera su propia contingencia es el dolor que Samuel Beckett (1906-1989) no sabe sobrellevar. El irlandés la despliega en este desafío que es Happy Days, desgrana el trascurrir de la existencia en falso tiempo muerto, expuesta a su propia destrucción. Escrito en 1960/61, funciona como reacción a una era "dorada" de falsa prosperidad consumista acunando lo banal, el materialismo hedonista en el Hemisferio Norte de post guerra. Ese que parecía no haber entendido la lección de la Historia inmediata. A los grandes textos dramáticos hay que comprenderlos en el cuadro de la circunstancia histórica, económica y social en que fueron concebidos.

Voy a extenderme lateralmente. Sobre el teatro de Beckett, el peor error es caer, como estudioso, como crítico, en tratar de explicárselo al espectador. Becket se interroga a sí mismo, siempre. Y las respuestas nutritivas son individuales. Cuando vamos a presenciar una re-presentación de sus obras, (de Los días felices ahora), conectamos sí o sí con un pensamiento concebido originalmente en otra diferente lengua (francés, el idioma de adopción, en este caso). Por otro lado, como "lectura" personal del director, del puestista, refleja los contactos que un versionador y el autor tuvieron y tienen, en mutuo roce de empatía. Las respuestas, el eco de los interrogantes lanzados al viento, hacia la sensibilidad del espectador, llegan pues intervenidos (en este caso, es en especial importante el proceso de apropiación, equivalencias o sustitución, suplantación (más sus eventuales cortes, síntesis etc.), intermediados por los otros intérpretes; los actores. En la versión que recibimos de Beckett el espectro se ha afinado y puesto en valor, el terrible efecto del humor en su vecindad con el absurdo cotidiano. La parte nueva que encontramos ahora por medio de Rubén Pires a través de Rita Terranova y Gerardo Baamonde, nos da una vez más, atractiva, una buena parte por un todo. Y aun así, lo que volvemos a pasar por nuestro propio tamiz produce un efecto singular, en cada uno de los sentados a su butaca. Encontrar sueño reparador al cabo de un día es la manera más conocida que usamos para suponer nuestros propios días, felices.

Detesto "explicar" un texto dramático, la didáctica no alcanza pero sin dudas, limita. En este caso, aun "criticar" se torna azaroso. Sospecho que lo que hay que evitar es apoderarse del material y modificar lo presenciado agregando una impronta personal al acto de la representación (para "explicar" están las monografías, los ensayos; las tesis al uso). Sé que esto parece un largo paréntesis, pero libera al espectador de la sujeción a la opinión de otro. Amen.

Winnie y Willie están ahí frente al público en medio de una de apariencia quieta. El pasado, pasó, el futuro será incierto, corto, asertórico y excluyente. El presente con su falso sentido de estabilidad es a lo que intenta Beckett inducirnos para que lo escuchemos mejor. Si nos aburrimos (puede suceder), nos distraemos (acaso suceda); si no evadimos, Beckett no es para nosotros. Nada se puede hacer sobre eso. Si caemos subyugados, como les acontece a Pires, Terranova y Baamonde, el propósito de toda esa traslación se habrá cumplido.

¿Es pesimista Beckett? Lo es, contrastado su sentir al optimismo de Winnie. Conocemos muchas lecturas, muchas versiones, muchas puestas en escena, muchas interpretaciones virtuosas sobre ese terrible ser que es Winnie. Esta que nos espera en El Tinglado Teatro ahora, es una diferente. Lo es en especial porque Pires estima el humor ácido, implícitamente irónico sobre los actos pequeños de los personajes. Beckett había leído en los 5o's al dramaturgo y poeta Racine (1639-1699). Los días felices como Comedia (Play), dan cuenta de esto. La protagonista de Beckett anima por inconciencia, aquello que en los roles Racine se dio en llamar el "minimalismo trágico". El 
de Winnie, por traerlo al caso. Conjeturo que Pires se reclina en parte sobre esto cuando imprime a la Winnie sobre Rita Terranova. Winnie se nos vuelve inquietantemente inmediata y no hay manera de evadir ya que la luz reflejada en su espejito en mano, nos enfoque. Una labor espléndida la de Rita Terranova, de riesgo consciente y aceptado, por lo audaz de ese nuevo modo cercano de encarnarla. Y de Gerardo Baamonde, en la misma tónica, similar enfoque. Un salto, una pirueta, y Beckett cae parado de nuevo con menos solemnidad, mejor vecindad junto a nosotros, los azorados habitantes de este dislate que parece ser el inicio del siglo XXI.
LOS DÍAS FELICES (Happy Days) 1961 El Tinglado Teatro (Mario Bravo 948, Caba). Miércoles 20:30 hs.

Ficha Artístico/Técnica

Autor: Samuel Beckett

Dramaturgia: Rubén Pires

Adaptación: Rubén Pires

Actúan: Gerardo Baamonde, Rita Terranova

Pelucas: Miriam Maneli

Diseño de maquillaje: Analía Arcas

Diseño de vestuario: Juan Miceli

Representante Del Autor: Marion Clara

Reizes De Weiss

Diseño de escenografía: Juan Miceli

Diseño de luces: Rubén Pires

Realización de vestuario: Myrian D' Onofrio Video: Ángel Jara

Fotografía: Pic By Lis Arte En Imagen

Diseño gráfico: Nahuel Lamoglia

Asistencia De Producción: Alma Curci, Mechi Lando

Supervisión dramatúrgica: Lucas Margarit Dirección: Rubén Pires 